\title{
Cloud Seeding at Medellin, Columbia, During the 1962-64 Dry Seasons
}

\author{
M. E. Lopez aNd W. E. Howell \\ W. E. Howell Associates, Lexington, Mass. \\ (Manuscript received 31 August 1964, in revised form 5 November 1964)
}

\begin{abstract}
Rapid growth in demand, doubling about every 12 years, led in 1961 to stringent rationing of hydroelectric power and potable water in Medellin, Colombia. After a preliminary study had shown that dryseason precipitation on the city's watersheds came principally from daytime convective clouds that showered only after surpassing the freezing level, and hence might be stimulated by silver iodide, cloud seeding was undertaken in the 1962, 1963 and 1964 dry seasons.

Evaluation by the usual target-control regression procedure indicated increases of 20 to 40 per cent, nominally significant at the one per cent level. A new approach to evaluation, based on the suggestion by Thom that seeding, if it increases rainfall, should affect mainly the scale parameter of the distribution, was developed and applied to one of the targets, deriving a separate estimate of 25 per cent increase, which falls slightly short of significance at the five per cent level.

Significance is compromised by some subjectivity, though this was minimized as much as possible, and by unavoidably imperfect randomization and lack of predetermined experimental design.

The cost of operations was equivalent to the economic return from a 2 per cent increase in streamfiow from the target watersheds. The indicated result overfulfilled the expectation extablished in advance of operations.
\end{abstract}

\section{Introduction}

Increase in population and industrialization of Medellin, Colombia, has caused its water use for domestic consumption and hydroelectric power to double approximately every 12 years in the recent past. Despite rapid development of new watershed areas, the city experienced stringent rationing of both electric power and domestic water supply during the 1961 dry season (approximately the first three and a half months of the year) and faced a critical shortage in the 1962 season while new dams were nearing completion. After a study of the feasibility of cloud seeding for rainfall stimulation carried out during the minor dry season in August 1961, the Empresas Publicas de Medellin, which operates the public utilities supplying both electricity and potable water to the city, decided that the near certainty of water shortage in 1962 outweighed the risk that cloud seeding might not help, and undertook a program of rainfall stimulation.

Operations were accordingly conducted for maximum effect consistent with reasonable cost, and the operation was not designed for statistical proof of the success or failure. As might be expected from a still short period of operations, the evidence for increased rainfall is inconclusive from a scientific viewpoint. It is amply sufficient, however, because of the high economic value of additional water, to fulfill the expectations established before operations began and to justify continued use of cloud seeding during seasons of expected water shortage.

\section{Physiography and climate of the target areas}

The Western Cordillera of the Andes, which forms a highland with an average elevation of a little over $3 \mathrm{~km}$, and a width between the Pacific coastal lowlands and the broad valley of the Rio Magdalena of about 200 $\mathrm{km}$, falls off rather abruptly about $150 \mathrm{~km}$ north of Medellin except for an outrider, the Sierra de Ayapel, that extends northward from its northeastern corner for another hundred kilometers or so at an elevation of about $2 \mathrm{~km}$. The main highland is split north-south by the valley of the Rio Cauca, which passes about $30 \mathrm{~km}$ west of Medellin and is in this part of its course relatively narrow and deep. The valley of the Rio Medellin also cuts into the highland, though less deeply, from the north-northeast. Except for these two steep-walled valleys, the region is one of graded upland surfaces and relatively gentle relief, with ridges rising six or seven hundred meters above broad, open valleys.

The larger of the two target areas is the watershed of the Rio Grande, occupying the central and southern portion of the section of the highland lying north of Medellin between the two valleys mentioned above, and supplies a hydroelectric plant. This watershed has an area of about $1200 \mathrm{~km}^{2}$. The second target called Piedras Blancas is a much smaller watershed, only about $28 \mathrm{~km}^{2}$, and is perched on the shoulder of another section of the highland just east and northeast of the city of Medellin. It is the main source of domestic water for the city and also powers a small hydroelectric plant. 
The map (Fig. 1) shows the location of the target and surrounding areas.

The region has two rainy seasons, corresponding broadly to the northward and southward march of the intertropical convergence zone across it, and two dry seasons, the major one corresponding to the northernhemisphere winter and extending usually from about late December to mid-April. At this time of year the northern trade-wind regime prevails over the area, with interruptions. A fully-developed trade-wind regime is marked by a shallow moist layer capped by a strong inversion and overlain by very dry warm air subsiding out of the Azores high. Cloud development is restricted to diurnal cumulus humilis, and a dense haze locally called "calima" under the inversion often restricts the visibility to $3 \mathrm{~km}$ or less even during the warmest part of the day. This regime is interrupted from time to time in a number of ways; by incursion of cooler air aloft, by local convergence and deepening in the moist layer, by temporary northward wandering of elements of the intertropical convergence, or by combinations of these; and during such interruptions diurnal clouds reach a higher stage of development and showers break out, especially where terrain favors local convection. Sometimes the rainfall continues, lighter and more drizzly, through the night, almost always ending before 0900E. Although the local patterns of cloud and shower development are very complex, a large proportion of the raininess is associated with relatively large-scale weather patterns, especially those governing convergence at the lower levels, in the same manner as was found to be true in other parts of tropical South America (Howell, 1953; Lopez and Howell, 1961).

\section{Local meteorology}

For study of the local meteorology, radiosonde and winds aloft observations from Bogota, $250 \mathrm{~km}$ to the southeast, were supplemented by local observations of winds aloft, both by pilot balloon and by nephoscope, by theodolite observation of zero-lift balloons, and by whole-sky time-lapse photography of cloud developments.

On days when cumulus congestus formed over the highlands, the cloud base was found to be at an elevation of approximately $3.7 \mathrm{~km}$, with a temperature typically of $10 \mathrm{C}$. Clouds with bases at this level were never observed to produce showers with a cloud depth less than $1.5 \mathrm{~km}$, which is to say that cloud tops almost always reached the freezing level before shower formation. The freezing level on the Bogota sounding during the dry season averaged $5 \mathrm{~km}$. During typical tradewind weather the wind aloft over the highlands averaged easterly about $15-20 \mathrm{kt}$ beneath the usual 3-km-high inversion, becoming lighter and variable, but still easterly, above it. Above $10 \mathrm{~km}$, westerlies occur frequently, although there does not seem to be a set rule for their occurrence. The winds above this elevation

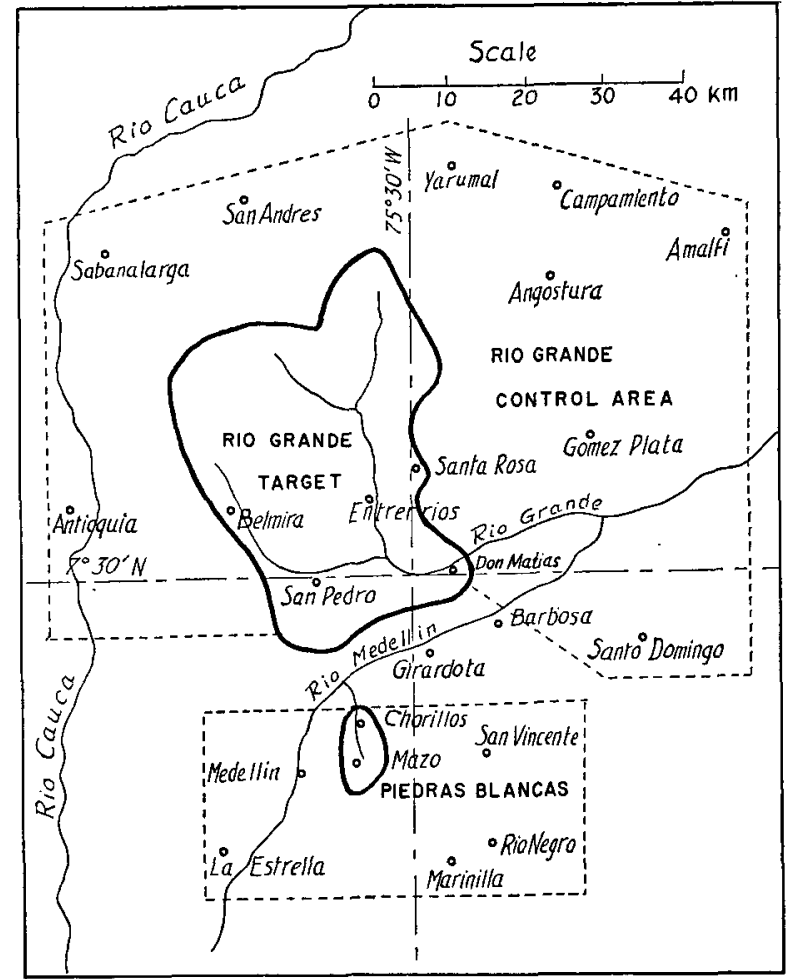

FIG. 1. Map of the rain stimulation target areas and corresponding control areas, showing locations of rain gage stations.

were, with few exceptions, always obtained from the RAWIN at Bogota where the reporting at this height of several 180-degree reversals between mandatory levels is not unusual. During departures from this trade regime, easterly-wave-like shifts occurred in the lower $10 \mathrm{~km}$, accompanied by thickening in the moist layer, the wind shifts ranging from southeast to southwest.

Pressure change analysis using the technique described by Lopez (1948) were of doubtful value here for 24-hour changes did not remove all the systematic pressure changes; but a simple integration of the precipitable water between the 700- and 400 -mb levels at Bogota, using a technique suggested by Solot (1939), was found to be of some value. For the two seasons that these values were charted they ranged between 5 and $23 \mathrm{~mm}$. It was found empirically that there was little chance for precipitation at Medellin when the precipitable water in this layer stayed below $12 \mathrm{~mm}$ and that values above $15 \mathrm{~mm}$ were almost always accompanied by rain. As with many similar rules-ofthumb, the day-to-day values of the precipitable water fell distressingly often in the doubtful in-between category making the rule only occasionally helpful as a forecasting aid, but it served well as an operational decision parameter.

Even during the dry season around Medellin, rainfall is heavy over the Pacific slope of the Western Cordil- 
lera, $100 \mathrm{~km}$ to the west, and very large cumulonimbus build-ups with cirrus crowns are a frequent feature of the distant western sky. Not infrequently the divergence aloft from these circulations is sufficiently energetic to carry dense cirrus eastward over Medellin. Likewise, during northward excursions of the inter-tropical convergence, strong cumulonimbus development takes place over the Eastern Cordillera, $300 \mathrm{~km}$ or so to the east and southeast, where these mountains present the first major barrier to the easterlies from the Orinoco basin. When perturbations of the usual wind system are present that bring air at middle and upper levels from these areas to Medellin, extensive cloudiness at middle levels often follows by several hours the diurnal maximum of convective activity, frequently accompanied by nocturnal rain as the decaying rain systems are carried past and possibly maintained by divergence at very high levels. This nocturnal raininess is a regular feature of the rainy seasons, which are of course also the seasons of maximum cumulonimbus development at these more remote sites.

Since airborne seeding was out of the question for economic reasons and there was little likelihood that seeding from the ground would reach the clouds responsible for nocturnal rain, a study was made of the relative contribution of day-time and night-time rains at San Pedro, in the Rio Grande watershed. At this station, during the rainy season, daytime rain $(0800 \mathrm{E}$ to $2000 \mathrm{E}$ ) accounted for 48 per cent of the hours of rainfall and 51 per cent of the accumulation; during the dry season, on the other hand, it accounted for 64 per cent of the rainy hours and for 79 per cent of the accumulation. It is concluded, therefore, that during the dry season the local convection, susceptible to seeding from smoke generators situated locally on the ground, is the preponderant producer of rain.

Visual observation, both from the ground and from airplanes, backed up by time-lapse photography, served to identify four major centers of convection, points where the first major convection of the day within a given region had a high probability of occurring, and a number of secondary centers. It was not obvious in every instance why these centers occupied the positions that they did, but they served empirically, nevertheless, as a basis for siting the smoke generators.

\section{Seeding operations}

Operations were originally scheduled for the dry season only, starting when the management decided that stimulation was desirable and continuing until the usual return of the rainy season in April would guarantee an ample water supply. During the 1962 and 1963 dry seasons the management also requested suspension of seeding operations during critical stages of construction of an earth-fill dam at a nearby site. There was thus a certain randomness in the actual dates of start and ending of operations and since the suspensions within the dry season were not chosen by the seeding operator because of. weather unfavorable for stimulation, it is possible to divide the operating period into seeded and unseeded days with some approximation to random choice.

After the 1962 operations, and when due consideration was given to increased deforestation at Rio Grande, to the difficulty of predicting the onset of the rainy season, and to the lack of adequate storage facilities, it was decided by the management that operations could be extended for short periods at the beginning and end of the rainy season in hopes of contributing materially to the water supply, in spite of lack of storage capacity by improving antecedent river conditions.

The smoke generators used were of a type that burns a string impregnated with silver and sodium iodide at the rate of $6 \mathrm{gm} \mathrm{hr}^{-1}$ with a production of about $5 \times 10^{11}$ nuclei per second at an activation temperature of $-10 \mathrm{C}$. Cloud seeding missions were conducted on a total of 355 days for one or both watersheds, totalling 9009 generator hours of seeding. Cloud seeding operations were conducted between the dates given in Table 1 .

Table 1. Dates of cloud seeding operations.

\begin{tabular}{cccc}
\hline \multicolumn{2}{c}{ Piedras Blancas target } & \multicolumn{2}{c}{ Rio Grande target } \\
Started & Ended & Started & Ended \\
\hline 9 Jan 1962 & 30 Apr 1962 & 9 Jan 1962 & 30 Jan 1962 \\
12 Dec 1962 & 19 Dec 1962 & 10 Feb 1962 & 23 Mar 1962 \\
28 Dec 1962 & 15 Apr 1963 & 18 Apr 1962 & 30 Apr 1962 \\
28 Dec 1963 & 30 Apr 1964 & 5 Jan 1963 & 15 Apr 1963
\end{tabular}

\section{Rainfall data}

The map, Fig. 1, shows the locations of the rain gages used in evaluation of the rain stimulation. Some of these gages are operated and the data published under the direction of the Department of Antioquia, while others are operated by Empresas Publicas de Medellin. Although there are now a number of additional gages operated by Empresas, these were installed too recently to serve the purpose of some of the analysis that follows. The gages within the watersheds lie generally in their lower parts and fail to represent the higher and rainier parts, but at least they are not greatly affected by weather conditions unrepresentative of the watersheds. The region from which a control area could be selected was limited on the west to the boundary of the highland west of the Cauca valley, where the rainfall regime is greatly influenced by the clouds on the Pacific slope; on the north by the end of the Andean highland; and on the south by the head of the broad upper part of the Cauca valley where the gages are influenced by a valley rather than a highland setting. To the east, in the direction from which the prevailing wind comes, the limit was set by the distance to which a useful degree of correlation with the watershed could be discerned, which is also influenced by the diminishing 
elevation: stations for which a sampling of the data showed a correlation estimated at less than 0.50 were rejected. Within the available region, all rain gages having an adequate period of record were included in the control area, with the exception of two, Girardota and Barbosa, that lie just south of the Rio Grande watershed where they were frequently within the area of expected influence of the silver iodide smoke. The control stations are, as to be expected, at lower elevations than the target: the average elevation of the rain gages on the Piedras Blancas target is $2420 \mathrm{~m}$, on the Rio Grande target $2390 \mathrm{~m}$ and on the control zone $1750 \mathrm{~m}$.

\section{Evaluation by target-control regression}

A covariance analysis of the scalar rainfall values was undertaken as one form of evaluation. Consideration was first given to daily rainfall as the argument of the analysis; but observation of the local weather led to the suspicion that daily rainfall in the dry season may alternate among a few typical patterns such that, if it rained at one certain station, rain would be unlikely at another certain station, and vice versa, so that the general expression of large-scale weather effects might not appear as a positive correlation between these two stations. Such was indeed found to be the case between, for example, Medellin and Chorrillos; the correlation coefficient for daily rainfall amounts between them was found to be -0.21 . Seasonal rainfall amounts (1 January to 15 April), on the other hand, were found to be well correlated positively but offered little flexibility in the analysis. Monthly amounts were therefore adopted as a workable compromise. The dry season generally starts in mid-December and the month of April usually sees the return of the rainy season. The monthly totals for either month can be representative in different years of either season. A study of the relationship of the rainfalls between target and control shows that the existing differences of elevation do not seem, in this area, to make any great difference as far as the time of onset or end of the rainy season as is the case, for instance in the northeast coast of Colombia where the rainy season may start a full month earlier at the 1500 -m level than at low-lying nearby areas. For this reason, it was decided to include also the transition months of December and April with the dry season months and to combine all months together in the correlations between target and control in an effort to augment the number of available historical points and improve the coefficient of correlation and the power of the test (Thom, 1957).

The maximum amount of available historical information (stations times seasons) corresponds to the period 1939-1960 for the Rio Grande target-control comparison (February 1950 excepted because of missing data), and to the period 1949-1960 for the Piedras Blancas

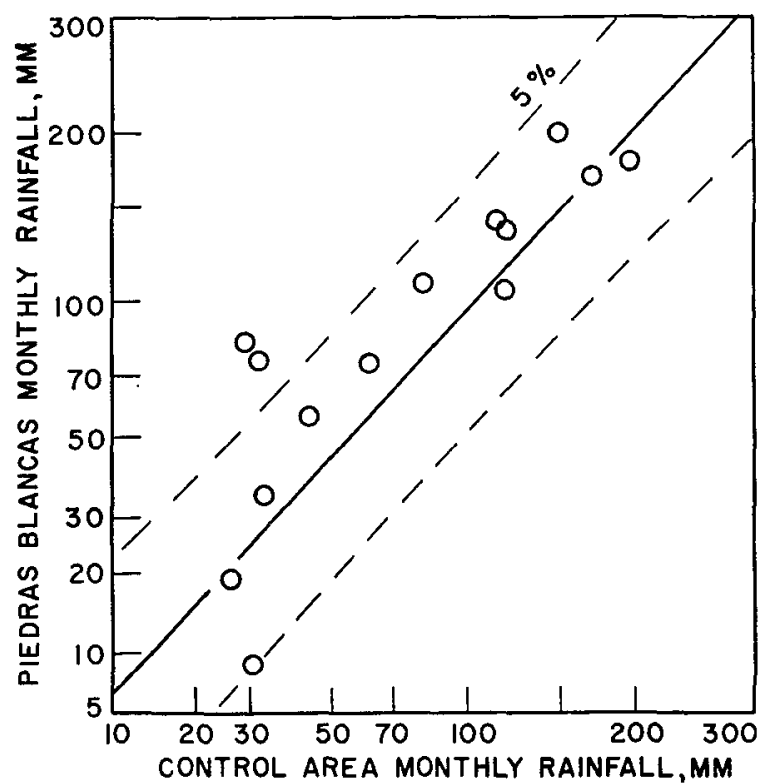

FIg. 2. Regression diagram of Piedras Blancas monthly rainfalls on the control area monthly rainfalls for 64 months, showing seeded months (whole and fractional). The 5\% confidence limits shown correspond to a one-tailed test.

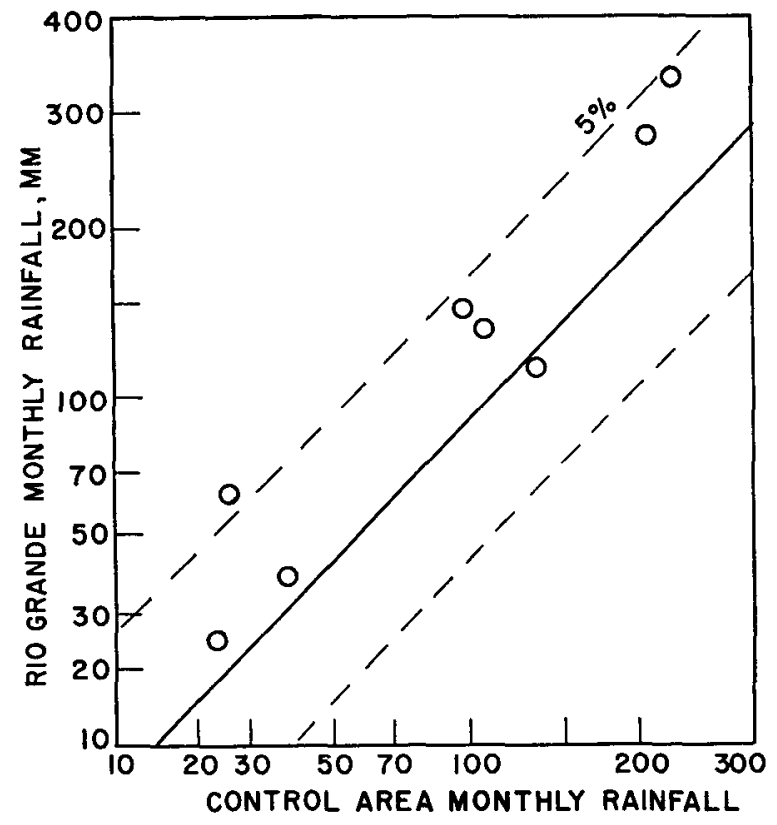

FIG. 3. Regression diagram of Rio Grande monthly rainfalls on the control area monthly rainfalls, showing experience of seeded months (whole and fractional).

comparison. The regression computations were therefore based on these periods.

The monthly rainfall amounts were transformed by a cube-root transformation (Stidd, 1953) to remove the natural skewness of the rainfall distribution and adapt the data to the application of normal-probability criteria. From each target, the regression of the target on the control rainfall was obtained, together with the 
standard deviations of the marginal distributions, the correlation coefficients, and the standard errors of estimate. The dispersion diagrams and regression lines are shown as Figs. 2 and 3.

Where only a fraction of a month was included in a seeded period, the target and control rainfall amounts were first divided by this fraction before making the cube-root transformation. A point was then found which was the weighted mean of this fictitious whole month and an average month, thus in effect making the conservative assumption that the entire variance was accumulated during the real-data fraction of the month.

The departures of the points representing the seeded and unseeded periods in 1962, including the points for fractional months, were subjected to the usual $t$ test, of the form

$$
t=\frac{y-y_{c}}{S_{y}}\left(\frac{N-1}{N+1+(x-\bar{x})^{2} / \sigma_{x}^{2}}\right)^{\frac{1}{2}}
$$

and the several $t$ values within each target area were combined according to Stouffer's method (Stouffer, 1941) into a $z$-test. Table 2 presents a list of symbols.

The statistical parameters and the results of the tests are shown in Table 3. Application of the usual statistical criteria indicates the increase of $21 \%$ on the smaller target significant at the $2 \%$ level, and the increase of $40 \%$ on the larger target significant at the $1 \%$ level. Circumstances possibly compromising these indications are discussed in the conclusions.

TABle 2. List of symbols.

\begin{tabular}{|c|c|}
\hline$k=$ number of rainy days in a & given season \\
\hline$K=$ number of trials & \\
\hline$n=$ number of days in the mon & nth not prohibited for seeding. \\
\hline$N=$ number of historical points & $s$ available in the regression \\
\hline$P=$ total average target precip & oitation for seeded season $(\mathrm{mm})$ \\
\hline$X=$ average control rainfall (m & $\mathrm{nm})$ \\
\hline$Y=$ average target rainfall $(\mathrm{mn}$ & m) \\
\hline$P_{c}=\underset{(\mathrm{mm})}{\text { predicted seasonal target }} \mathrm{r}$ & rainfall if no seeding had occurred \\
\hline $\begin{aligned} Y_{c} & =\text { predicted target rainfall if } \\
x & =Y^{\frac{1}{3}} ; \quad y=Y^{3} ; \quad y_{c}=Y_{c}^{\frac{1}{3}} ; \quad p\end{aligned}$ & $\begin{array}{l}\text { no seeding had occurred (mm) } \\
p=P^{0.7904} ; \quad p_{c}=P_{c}^{0.7904}\end{array}$ \\
\hline$r_{x, y}=$ coefficient of correlation of & $f(x, y)$ \\
\hline$r_{k, p}=$ coefficient of correlation of & $f(k, p)$ \\
\hline$\sigma_{x}=$ standard deviation of $x$ & $\sigma_{p}=$ standard deviation of $p$ \\
\hline$\sigma_{y}=$ standard deviation of $y$ & \\
\hline$S_{y}=\sigma_{y}\left(1-r_{x, y^{2}}\right)^{\frac{3}{3}}=$ standard err & ror of estimate of $y_{0}$ \\
\hline$S_{p}=\sigma_{y}\left(1-r_{k, p^{2}}\right)^{\frac{1}{2}}=$ standard err & ror of estimate of $p_{c}$ \\
\hline$t=$ Student's statistic correcte & ed for size of sample (see text) \\
\hline$z=$ Stouffer's statistic $=\Sigma t / \sqrt{K}$ & \\
\hline
\end{tabular}

\section{Evaluation by specific-raininess regression}

The idea of an entirely different approach to evaluation derived from a suggestion by Thom (1957) that an artificial increase due to seeding should show up, if at all, as an increase in the scale parameter $\beta$ when the daily rainfall distribution at an affected station can be fitted by an incomplete gamma function. Berndt (1957) showed that if this is the case, and when target data alone are used, a criterion suggested originally by Bayes can be modified to show that if the seeding is successful, the average rainfall per rainy day should be increased beyond a certain level which varies depending on the economic value of the rain. This, in turn, leads to the idea that specific raininess (the average rainfall per

Table 3. Results of target-control evaluation during 1962-64.

\begin{tabular}{|c|c|c|c|c|c|c|}
\hline \multirow[b]{3}{*}{ Month } & \multicolumn{5}{|c|}{$\begin{array}{c}\text { 3a. Results for Piedras Blancas during seeded } \\
\text { days for individual months. }\end{array}$} & \multirow[b]{3}{*}{$t$} \\
\hline & \multicolumn{2}{|c|}{$y_{c}=1.099 x-0.520$} & \multicolumn{3}{|c|}{$r=0.871 \quad S_{y}=0.530$} & \\
\hline & $n$ & $X$ & $Y$ & $Y_{c}$ & $Y-Y_{c}$ & \\
\hline $\operatorname{Tan} ' 62$ & 23 & 18.0 & 62.4 & 13.2 & 49.2 & 2.73 \\
\hline Feb '62 & 28 & 33.9 & 38.7 & 28.0 & 10.7 & 0.64 \\
\hline Mar '62 & 31 & 82.5 & 109.7 & 77.5 & 32.2 & 0.98 \\
\hline Apr ' 62 & 30 & 149.0 & 202.7 & 149.4 & 53.3 & 1.04 \\
\hline Dec '62 & 12 & 54.4 & 76.6 & 54.2 & 22.4 & 0.73 \\
\hline Jan '63 & 31 & 26.6 & 19.3 & 21.0 & -1.7 & -0.14 \\
\hline Feb '63 & 28 & 121.5 & 138.5 & 119.3 & 19.2 & 0.46 \\
\hline Mar '63 & 31 & 120.3 & 106.1 & 118.0 & -11.9 & -0.31 \\
\hline Apr '63 & 15 & 109.9 & 113.8 & 114.2 & -0.4 & -0.02 \\
\hline Dec ' 63 & 5 & 6.6 & 11.8 & 5.6 & 6.2 & 0.69 \\
\hline Jan '64 & 31 & 30.7 & 8.9 & 24.9 & -16.0 & -1.56 \\
\hline Feb '64 & 29 & 32.1 & 75.9 & 26.3 & 49.6 & 2.32 \\
\hline Mar '64 & 31 & 44.4 & 55.7 & 38.3 & 17.4 & 0.83 \\
\hline Apr '64 & 30 & 196.2 & 181.8 & 201.8 & -20.0 & -0.37 \\
\hline Total & 355 & 1026.1 & 1201.9 & 991.7 & 210.2 & 8.02 \\
\hline
\end{tabular}

Indicated increase $=21 \% \quad z=8.02 / \sqrt{14}=2.14$

3b. Results for Rio Grande during seeded days for individual months. $y_{\mathrm{c}}=1.045 x-0.380 \quad r=0.859 \quad S_{y}=0.603$

\begin{tabular}{rrrrrrr} 
Month & $n$ & \multicolumn{1}{c}{$X$} & \multicolumn{1}{c}{$Y$} & \multicolumn{1}{c}{$Y_{c}$} & \multicolumn{1}{c}{$Y-Y_{c}$} & \multicolumn{1}{c}{$t$} \\
\hline Jan '62 & 22 & 26.9 & 27.4 & 21.8 & 5.6 & 0.48 \\
Feb '62 & 19 & 17.8 & 42.3 & 13.7 & 28.6 & 2.14 \\
Mar '62 & 23 & 72.9 & 110.0 & 65.2 & 44.8 & 1.70 \\
Apr '62 & 13 & 90.6 & 120.0 & 85.4 & 34.6 & 0.76 \\
Jan '63 & 27 & 20.7 & 21.3 & 15.7 & 5.6 & 0.64 \\
Feb '63 & 28 & 108.3 & 134.7 & 97.4 & 37.3 & 1.42 \\
Mar '63 & 31 & 134.0 & 115.6 & 122.5 & -6.9 & -0.26 \\
Apr '63 & 15 & 114.0 & 167.6 & 108.2 & $\underline{59.4}$ & 0.12 \\
Total & $\mathbf{1 7 8}$ & $\overline{585.5}$ & $\overline{738.9}$ & $\overline{529.9}$ & $\underline{209.0}$ & $\frac{7.00}{}$
\end{tabular}

Indicated increase $=39.5 \% \quad z=7.00 / \sqrt{8}=2.48$

3c. Results for all unseeded days, December through A pril at both targets for period 1961-63.

\begin{tabular}{ccccc}
$\begin{array}{c}\text { Unseeded } \\
\text { days }\end{array}$ & $\Sigma X$ & $\Sigma Y$ & $\Sigma Y_{c}$ & $z$ \\
\hline 162 & 510.2 & 510.9 & 479.4 & 0.36 \\
\hline
\end{tabular}


rainy day) should be subject to less natural variation than the average rainfall. It was possible to test this only for the Piedras Blancas target since much of the needed daily rainfall data are not available for Rio Grande. At Piedras Blancas the 13 dry seasons (1 January to 15 April) preceding 1962, showed a strong relationship between the number of rainy days and the total season rainfall, but a very weak one (without a significant correlation) between the seasonal average rainfall and the seasonal average of specific raininess. This makes it possible to obtain a regression of seasonal rainfall on the number of rainy days. For physical considerations, it is desirable to transform the rainfall so that the best-fit, least-squares line of the regression passes through the origin. This can be accomplished by transforming the seasonal rainfall $P$ into $p=P^{q}$ where $q$ is the root, between 1 and 0 , of the equation

$$
\frac{\Sigma k^{2}}{\Sigma k} \Sigma p^{q}-\Sigma k p^{q}=0
$$

in which $k$ represents the number of rainy days per season and the sums extend over the available seasons. This transformation also helps to normalize the seasonal precipitation distribution.

For the 13 available seasons, $q=0.7904$ and the resulting regression is shown in Fig. 4. Table IV shows the results of the combined 1962-64 seasons against this regression. These results indicate that the total rainfall was $25 \%$ greater than would be expected on the basis of the observed number of rainy days. They also seem to support Thom's (1957) hypothesis of scale changes for seeding effects, for if seeding produced more rainy days the tendency to observe increases with this approach would be greatly weakened. A combined $z$ test using the technique described by Stouffer (1949) shows that the probability of simultaneous chance occurrence of such large positive deviations is 0.062 or about one in sixteen.

The evaluation method just outlined offers intriguing possibilities when only target data are available. The power of this test can be appreciated if we apply the usual test of comparing the seeded target precipitation with the corresponding historical mean for the same months during unseeded years. An increase of $12 \%$ in

TABle 4. Result of specific raininess evaluation.

$$
P_{c}=1.687 k, \quad r=0.817, \quad S_{p}=15.79
$$

\begin{tabular}{cccccc}
\hline \hline Season & $k$ & $P$ & $P_{c}$ & $\left(P-P_{c}\right)$ & $t$ \\
\hline 1962 & 41 & 263.4 & 212.8 & 50.6 & 0.732 \\
1963 & 61 & 400.2 & 351.6 & 48.6 & 0.638 \\
1964 & 41 & $\frac{303.8}{212.8}$ & $\frac{91.0}{197.2}$ & $\frac{1.295}{2.665}$ \\
& $\overline{143}$ & 967.4 & 777.2 & 190.2 & \\
\multicolumn{7}{c}{ Indicated increase $24.5 \% ;$} & $z=1.54$ & \\
\hline
\end{tabular}

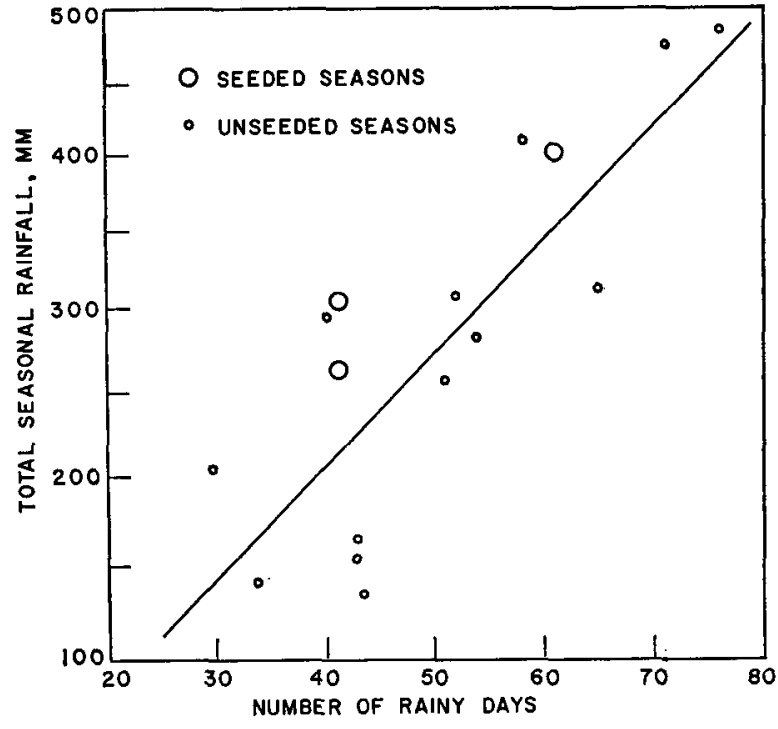

FIG. 4. Regression diagram of Piedras Blancas seasonal total rainfalls (1 January to 15 April) on number of rainy days in the target area for unseeded seasons, showing experience of seeded seasons (actual duration of seeded season-see text).

rainfall for the three analyzed seasons is indicated but with a combined $z$ value of only 0.53 , indicating that there is an entirely inconclusive probability of 0.30 that such increase might be due to chance occurrence. The comparison with the mean fails to extract all possible information from these data, i.e., the fact that each year varies in intrinsic storminess. In this case, it has been possible to reduce the variance of the rainfall estimated if seeding had not taken place by more than sixty per cent by using thesuggested rainfall transformation and the regression on rainy days.

\section{Conclusions}

Close observation of the development of convective clouds and rainfall in the target area during the dry season supported the idea that the greater part of the rainfall results from local convective systems that can be seeded from smoke generators sited on the ground upwind from identifiable centers of convection. Subjective observations strongly suggested that clouds in the seeded areas exhibited an unusual tendency to develop a snowy appearance in their upper parts.

The conditions under which the program was carried out precluded establishing the design of the statistical experiments in advance, and indeed it is doubtful if enough was known about the area ahead of time to have done so with much chance of applying a powerful test. The tests as they were carried out were compromised by the subjectivity in selection and treatment of the data, although every effort was made to avoid subjectivity, for example by including in the control area all stations within rather easily recognizable physiographic regions. 
Furthermore all target-control choices were made before the beginning of the 1963 operating season, freezing the "rules of the game" at that time. The analysis would be compromised if there were to have been a secular change in the natural target-control relationship or some synoptic peculiarity of the 1962-64 seasons affecting it, though the authors know of no reason to suspect such disturbances, and indeed the lack of any considerable departure from the regression during more or less randomly determined unseeded intervals within the operating period (cf. Table $3 \mathrm{c}$ ) argues against such a likelihood. Subjectivity is further reduced in the specific-raininess regression analysis by the self-defining nature of the target, though the choice of the method does itself represent a subjective decision since this application was the first that the authors have made of it.

Balanced against these possibly compromising circumstances is the agreement between two radically different tests and the consistent nature of the results from season to season and from target to target, coupled with the observations of cloud modification of a sort to be expected from ice-nuclei seeding.

An analysis made in collaboration with the Empresas Publicas of the economic value of additional water during the dry season indicated that a two per cent increase of rainfall would pay the cost of the weather modification program. On this basis, by application of the Bayes procedure (Berndt, 1957), it was possible continuously during the program to arrive at an objective recommendation whether the economic risk of continuing the operation was justified by the economic risk of stopping it and foregoing the degree of increase currently being indicated. This objective procedure recommended continuation at all times during the project, and ended up indicating an increase many times larger than that required to recommend continuation.

The dams that were under construction during the 1961-62 seasons were completed in 1963 and have eliminated the electric power shortage. Seeding was continued during 1964 at Piedras Blancas for alleviation of potable water shortage.

Acknowledgments. This work was made possible through the financial support of Empresas Publicas de Medellin. Special credit is due to Sr. Juan Wiesner for invaluable assistance in its prosecution and for conducting the operations for Piedras Blancas during 1964.

\section{REFERENCES}

Berndt, Gerald D., 1957: An evaluation of commercial cloudseeding operations conducted during the summer months in South Dakota. Final Report of the Advisory Committee on Weather Control, Vol. II. Tech. Report No. 5, 69-86.

Howell, W. E., 1953: Local weather of the Chicama valley (Peru). Archiv Meteor. Geophys. u. Bioklim., 5, 551-588.

Lopez, Manuel E., 1948: A technique for detailed radiosonde analysis in the tropics. Bull. Amer. Meteor. Soc., 29, 227-236.

_- , and W. E. Howell, 1961: The campaign against windstorms in the banana plantations near Santa Marta, Columbia, 1956-57. Bull. Amer. Meteor. Soc., 42, 265-276.

Solot, Samuel B., 1939: Computation of depth of precipitable water in a column of air. Mon. Wea. Rev., 67, 100-103.

Stidd, C. K., 1953: Cube root normal precipitation distributions. Trans. Amer. Geophys. Union, 34, 31-35.

Stouffer, S. A., et al. 1949: The American Soldier. Adjustment During Army Life. Princeton University Press, Vol. II, p. 45.

Thom, H. C. S., 1957: A statistical method of evaluating augmentation of precipitation by cloud seeding. Final Report of the Advisory Committee on Weather Control, Vol. II, Tech. Report No. 1, 5-24. 